\title{
Social behaviors of several ocypodoid crabs observed in mangrove swamps in southern Thailand
}

Keiji Wada

\begin{abstract}
The social behaviors of crabs in the families Dotillidae and Macrophthalmidae inhabiting mangrove swamps in southern Thailand were observed in the field. The cheliped motion and duration of the waving display were determined for four dotillid crabs (Dotillopsis brevitarsis, Ilyoplax delsmani, Ilyoplax gangetica, and Ilyoplax orientalis) and two macrophthalmid crabs (Macrophthalmus erato and Macrophthalmus pacificus), and their motion patterns were compared with those of congeneric species. The sequential events of coupling by a male and a female were observed in D. brevitarsis, I. gangetica, and Ilyoplax obliqua. Fighting events were noted for D. brevitarsis, I. gangetica, I. obliqua, and M. erato. A threat display based on the vertical movement of the chelipeds was observed in the dotillid species Dotilla myctiroides. The chela-quivering display by male I. obliqua was described based on the cheliped motion and the context in which the display occurred.
\end{abstract}

Key words: dotillid crabs, macrophthalmid crabs, mangrove swamp, sexual behavior, Thailand, waving display

\section{Introduction}

Intertidal ocypodoid crabs exhibit developed social behaviors, such as diversified visual displays (e.g., waving displays) (Crane, 1957; Schöne, 1968; Kitaura et al., 2006; Kitaura \& Wada, 2006), construction activities for territorial defense or courtship (Wada, 1994; Christy et al., 2002), and cooperative behaviors (Backwell \& Jennions, 2004; Fujishima \& Wada, 2013). Among ocypodoid crabs, the families Dotillidae and Macrophthalmidae, as well as the family Ocypodidae, exhibit high levels of diversity in the mangrove swamps of Southeast Asia (Serène, 1968; Tan \& Ng, 1994), but descriptions of their social behaviors such as waving displays, mating behavior, and fighting behavior are limited (Tweedie, 1950; Kosuge et al., 1994a, 1994b; Kitaura et al., 2006; Kitaura \& Wada, 2006), although the mating (Murai et al., 1995; 1996, 2002; Koga et al.,
1999; Weis \& Weis, 2004) and fighting (Koga et al., 1999; Tina et al., 2015) behaviors of fiddler crabs of the family Ocypodidae have often been studied.

This paper presents observational notes on the social behaviors of waving display, threat display, chela-quivering display, fighting, burrow usurpation and mating, which were recorded for six dotillid species (Dotilla myctiroides, Dotillopsis brevitarsis, Ilyoplax delsmani, Ilyoplax gangetica, Ilyoplax obliqua, and Ilyoplax orientalis) and two macrophthalmid species (Macrophthalmus erato and Macrophthalmus pacificus) in mangrove swamps of southern Thailand, and these behaviors are compared with those of related species.

\section{Materials and Methods}

Observations of the social behaviors of eight ocypodoid species were conducted in man- 


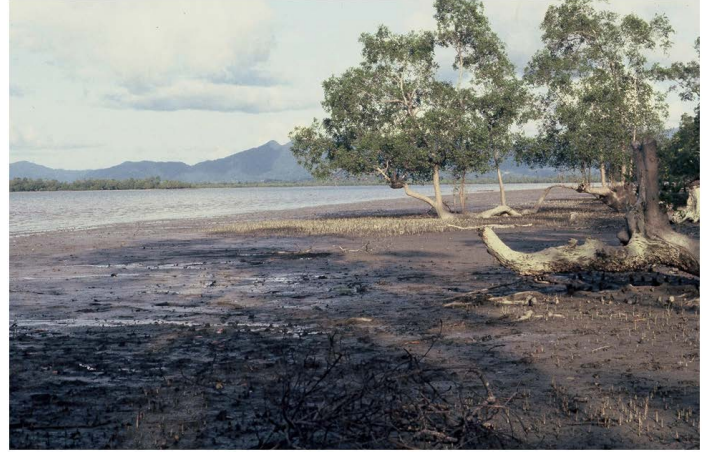

Fig. 1. A photograph showing the study site at the mangrove swamp of Hatsaikhao, Ranong, Thailand.

grove swamps of Hatsaikhao $\left(9^{\circ} 53^{\prime} \mathrm{N}, 98^{\circ} 33^{\prime} \mathrm{E}\right)$ (Fig. 1) and Kapoe $\left(9^{\circ} 32^{\prime} \mathrm{N}, 98^{\circ} 30^{\prime} \mathrm{E}\right)$, Ranong, southern Thailand, from November 22 to December 19, 1982. The waving display by six species (D. brevitarsis, I. delsmani, I. gangetica, I orientalis, M. erato and $M$. pacificus) and the chela-quivering display by $I$. obliqua were recorded with an $8-\mathrm{mm}$ video camera. The display motions were described based on the recordings, and the durations of the motions were determined based on the number of frames $(0.04 \mathrm{~s}$ or $0.06 \mathrm{~s}$ per frame). The threat display by $D$. myctiroides, fighting by $I$. gangetica, I. obliqua and M. erato, burrow usurpation by $D$. brevitarsis, and mating by $D$. brevitarsis, I. gangetica and I. obliqua were noted on the sequential events. The air temperature during the study period ranged from $22.0^{\circ} \mathrm{C}$ to $39.2^{\circ} \mathrm{C}$.

\section{$\square$ Results and Discussion}

\section{Dotilla myctiroides}

Threat displays directed at neighboring crabs were observed on seven occasions. When two crabs were close to each other, one crab bounced its chelipeds up and down for two or three bouts, directing this behavior toward the neighbor. The display was directed from a male to a male (two occasions), a male to a female (two occasions), a female to a male (two occasions),

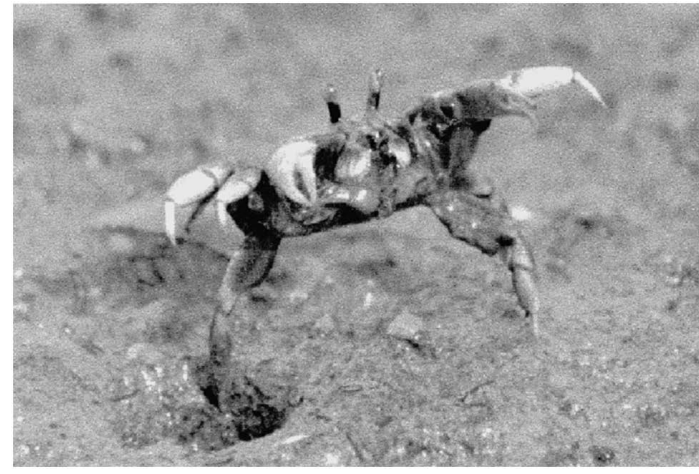

Fig. 2. Posture at pause at the maximum elevation of the waving display by Dotillopsis brevitarsis.

and a male to another species (one occasion). The cheliped motion during one bout was similar to the vertical type of waving display observed in Ilyoplax (Kitaura \& Wada, 2006). The threat display appeared to be similar to the post-combat display by the winner recorded for D. myctiroides by Tweedie (1950). Threat displays based on the vertical movement of chelipeds have been observed in another dotillid, Scopimera inflata (Fielder, 1970).

\section{Dotillopsis brevitarsis}

The waving display by male crabs began with the abrupt raising of the whole body, with both chelipeds and several ambulatory legs extended, off the ground, to the upper to lateral direction, followed by a pause at the maximum elevation (Fig. 2). Then, the body was suddenly lowered to the initial position. The wave duration ranged from $1.17 \mathrm{~s}$ to $1.83 \mathrm{~s}$ (mean: $1.57 \mathrm{~s}$ ), with a pause duration ranging from $0.42 \mathrm{~s}$ to $0.83 \mathrm{~s}$ (mean: $0.62 \mathrm{~s}$ ) (19 displays in four males). This waving motion can be categorized as a vertical type of waving display, similar to the genus Ilyoplax (Kitaura \& Wada, 2006), but different from Ilyoplax in that some ambulatory legs are lifted upward to the level of the eye stalks. A vertical type of waving display involving a pause at the maximum elevation in dotillid crabs has been reported only in Ilyoplax dentimerosa (Kitaura \& Wada, 2006). The 
pause style differs between $D$. brevitarsis and $I$. dentimerosa in that the former extends the chelipeds and legs more conspicuously.

Mating behavior was observed on one occasion. A wandering female approached a male that directed his waving toward her. The female was close to the male, and both crabs touched each other with their legs. Subsequently, the male moved slightly away from his burrow, which was followed by the female's entry into the male's burrow. The male, then, succeeded the female into his burrow. About $3 \mathrm{~min}$ later, the male emerged from the burrow and plugged the burrow by gathering surface sediments around the burrow entrance. Such underground coupling, in which the male entices the female to enter the male' burrow, is the same as that reported in other dotillid crabs of the genus Ilyoplax, such as I. pusilla (Wada, 1981), I. gangetica (Kosuge et al., 1994a), and I. orientalis (Kosuge et al., 1994b).

Burrow usurpation was observed on four occasions. A burrowless crab approached the burrow holder, which fled into its own burrow. Subsequently, the burrowless crab entered the burrow. After a short duration, the burrow holder re-emerged on the surface and began to wander, abandoning the burrow. Such burrow usurpation without fighting on the ground surface is the same as that of Ilyoplax pusilla (Wada, personal observation) but differs from that of Scopimera globosa, in which the burrow usurpation involves fighting between the burrow holder and the burrowless crab on the ground surface (Ida \& Wada, 2017).

\section{Ilyoplax delsmani}

The waving display by the male crab was performed by raising both chelipeds vertically and lowering to the initial position (Fig. 3), which can be categorized as a vertical type of waving display (Kitaura \& Wada, 2006). The wave duration ranged from $0.14 \mathrm{~s}$ to $0.46 \mathrm{~s}$ (mean: $0.29 \mathrm{~s}$ ) (88 displays by seven males). The wave motion was the same as that de-
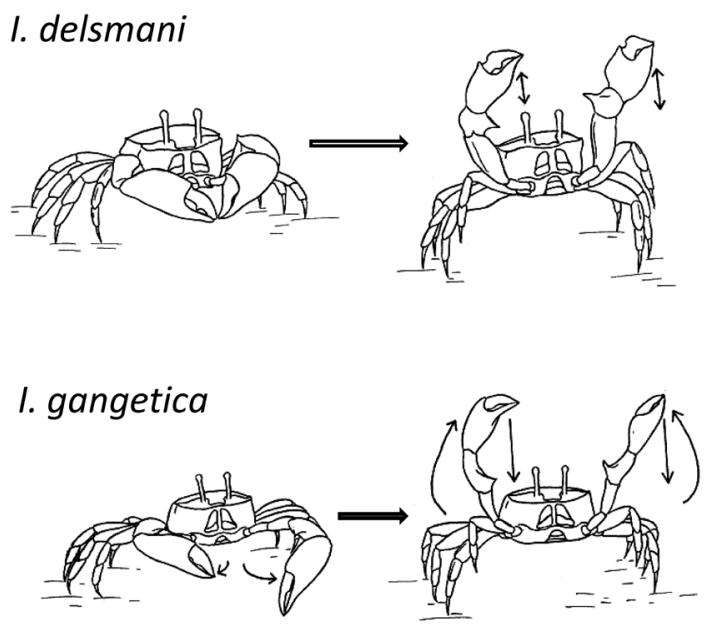

Fig. 3. Waving postures of Ilyoplax delsmani and Ilyoplax gangetica at the early stage (left) and the maximum elevation (right). The arrows beside the cheliped represent the direction of the cheliped movement.

scribed by Kosuge et al. (1994b).

\section{Ilyoplax gangetica}

Males performed the waving display by extending both chelipeds laterally until the tips pointed upward and the chelipeds unfolded and then abruptly lowered vertically (Fig. 3), which can be categorized as a circular type of waving display (Kitaura \& Wada, 2006). At the maximum elevation, the first ambulatory legs were lifted off the ground. The wave duration ranged from $0.22 \mathrm{~s}$ to $0.72 \mathrm{~s}$ (mean: $0.45 \mathrm{~s}$ ) (113 displays by ten males). The waving motion was the same as that described by Kosuge et al. (1994b).

Mating behavior was observed on one occasion. When a wandering female approached a male, he directed his waving toward her. The female moved closer to the male when the male presented quivering chela by trembling his extended chelipeds. Subsequently, the male entered his burrow, which was followed by the female's entry into his burrow. Thereafter, the female re-emerged from the burrow and left the burrow to wander. Underground coupling through male-first entering into the burrow has 


\section{1. obliqua}
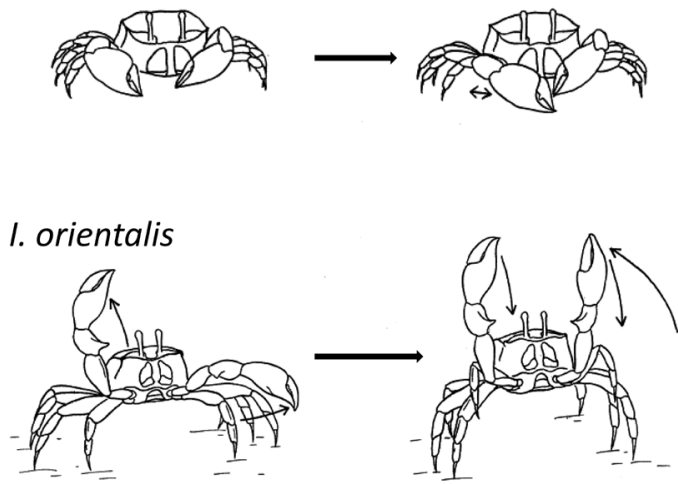

Fig. 4. Chela quivering display of Ilyoplax obliqua and waving postures of Ilyoplax orientalis at the early stage (left) and the maximum elevation (right). The arrows beside the cheliped represent the direction of the cheliped movement.

been observed in other species of Ilyoplax (Wada, 1981; Kosuge et al., 1994b; Wada et al., 1996).

Fighting between a burrow-holding male and a wandering male was observed on one occasion. A wandering male approached a burrowholding male and the two males intertwined with each other, which led to the upper extension of both chelipeds by the both combatants. The fighting ended when one combatant retreated. The winner performed the waving display towards the loser.

\section{Ilyoplax obliqua}

The waving display involving the rhythmic motion of the whole body with chelipeds, was not observed in this species, but a chela-quivering display was observed in male crabs, as reported in Kosuge et al. (1994b). The display was made by repeatedly moving either cheliped laterally (Fig. 4). The number of cheliped movements in one bout ranged from 9 to 19 (mean: 13.9). The duration of the quivering display ranged from $2.17 \mathrm{~s}$ to $4.44 \mathrm{~s}$ (mean: $3.15 \mathrm{~s})$ (16 displays by six males). The quivering display was performed by a burrow-holding male towards an approaching wanderer (four occasions), by a fight winner after combat (12 occasions), and by a male approaching a female (four occasions). The contexts in which the display occurred indicated that the display was associated with threatening behavior and courtship. The chela-quivering display is known in other eight congeneric species (Kosuge et al., 1994b, Kitaura \& Wada, 2006).

Mating behavior was observed on three occasions, wherein the coupling was completed by the male's entry into the female's burrow. A male approached a female as he directed a chela-quivering display toward her. The female entered her burrow, followed by the male's entry into the burrow. Burrow plugging, which is commonly observed in other species of Ilyoplax (Wada, 1981; Kosuge et al., 1994b), did not result in the successful entry of the couple into the burrow. Coupling by the male's entry into the female's burrow has been observed in a congeneric species, Ilyoplax dentimerosa (Wada et al., 1996).

Fighting was observed only between similarly sized male crabs (seven occasions). The two combatants approached and faced each other and intertwined their chelipeds with each other. Then, the two crabs tapped the outer surface of the chela of the opponent with one cheliped (usually on the right side). Fighting ended when one combatant retreated, after which the winner usually performed the quivering display.

\section{Ilyoplax orientalis}

Male crabs performed an asymmetrical motion waving display (Fig. 4), as described by Kosuge et al. (1994a) and Kitaura and Wada (2006). Initially, one cheliped was raised vertically until unflexed, which was followed by the movement of the other cheliped from a lateral to an upward position. At the maximum elevation, both chelipeds were directed upward, with the whole body extended upward and the first ambulatory legs lifted off the ground. Fi- 

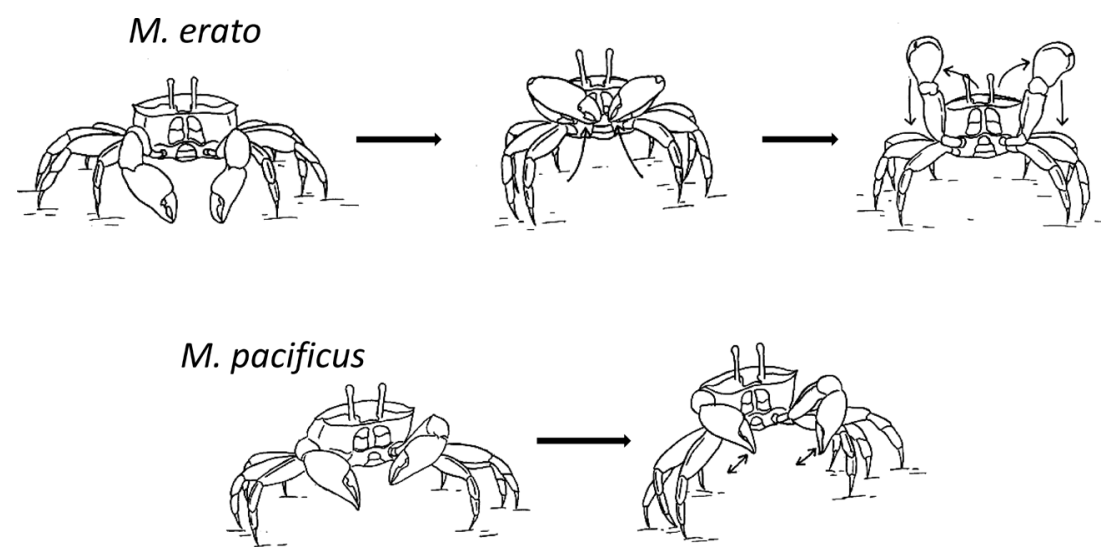

Fig. 5. Waving postures of Macrophthalmus erato and Macrophthalmus pacificus at the early stage (left) and the maximum elevation (right). The arrows beside the cheliped represent the direction of the cheliped movement.

nally, both chelipeds were lowered vertically to the initial position. The wave duration ranged from $0.78 \mathrm{~s}$ to $1.38 \mathrm{~s}$ (mean: $1.05 \mathrm{~s})$ (41 displays by two males). In the successive waves by each waver, the first-raised cheliped was on the right side for 13 waves and on the left side for seven waves in one male, and it was on the right side for 13 waves and the left side for eight waves in the other male.

\section{Macrophthalmus erato}

Male crabs performed a lateral forwardpointing type of waving display, as classified by Kitaura et al. (2006) (Fig. 5). The display began with the inward movement of both chelipeds, and then the chelipeds were raised forward until they were unflexed. At the maximum elevation, the chelipeds were positioned above the carapace, and the body was raised upward on extended legs. Finally, both chelipeds were lowered laterally. The wave duration ranged from $1.08 \mathrm{~s}$ to $1.67 \mathrm{~s}$ (mean: $1.55 \mathrm{~s}$ ) (eight displays by six males). Lateral forwardpointing types of waving have been observed in other macrophthalmids such as Macrophthalmus brevis, M. boscii, and M. quadratus (Kitaura et al., 2006).

Fighting between males was observed on one occasion. The two combatants faced and grasped each other. During the fighting, the lat- eral extension of the chelipeds, which is known in other macrophthalmids, such as Macrophthalmus abbreviatus, M. brevis, and M. latifrons (Kitaura \& Wada, 2004), was not observed.

\section{Macrophthalmus pacificus}

Males or females performed the waving display by a simple up-down movement of the flexed chelipeds (Fig. 5), as observed by Zucker (1988) and Kitaura \& Wada (2004). The flexed chelipeds were raised forward and lowered vertically, classified as the vertical forward-pointing type of waving display (Kitaura \& Wada, 2004). However, several crabs exhibited cheliped-unflexing, with the lifting of the second ambulatory legs off the ground at the maximum elevation. The vertical wave with chelipeds unflexed was observed in smaller crabs, as reported by Kitaura \& Wada (2004). The wave duration ranged from $0.72 \mathrm{~s}$ to $1.06 \mathrm{~s}$ (mean: $0.88 \mathrm{~s}$ ) (20 displays by eight crabs).

\section{Acknowledgments}

I would like to thank Dr. K. Ogino, Dr. A. Komiyama, Dr. S. Sabbasri, Dr. S. Aksonkoae, Ms. P. Thanaskarn, Mr. J. Konsangchai, and the staff of the National Research Council, the Royal Forest Department, and the Phuket Ma- 
rine Biological Center for their support of this study in Thailand. My thanks also go to two anonymous reviewers and Dr. A. Asakura, who provided useful comments to the manuscript. This work was supported financially by a Grant-in-Aid for Overseas Scientific Survey from the Japan Ministry of Education, Science and Culture.

\section{Literature Cited}

Backwell, P. R. Y., \& Jennions, M. D., 2004. Coalitions among male fiddler crabs. Nature, 430: 417.

Christy, J. H., Backwell, P. R. Y., Goshima, S., \& Kreuter, T. J., 2002. Sexual selection for structure building by courting male fiddler crabs: an experimental study of behavioral mechanisms. Behavioral Ecology, 13: 366374.

Crane, J., 1957. Basic patterns of display in fiddler crabs (Ocypodidae, genus $U c a$ ). Zoologica, 42: 69-82.

Fielder, D. R., 1970. The feeding behaviour of the sand crab Scopimera inflata (Decapoda, Ocypodidae). Journal of Zoology, London, 160: 35-49.

Fujishima, Y., \& Wada, K., 2013. Allocleaning behavior by the sentinel crab Macrophthalmus banzai: a case of mutual cooperation. Journal of Ethology, 31: 219-221.

Ida, H., \& Wada, K., 2017. Aggressive behavior and morphology in Scopimera globosa (De Haan, 1835) (Brachyura: Dotillidae). Journal of Crustacean Biology, 37: 125-130.

Kitaura, J., Nishida, M., \& Wada, K., 2006. The evolution of social behaviour in sentinel crabs (Macrophthalmus): implications from molecular phylogeny. Biological Journal of the Linnean Society, 88: 45-59.

Kitaura, J., \& Wada, K., 2004. Allocleaning, fighting, waving and mating behavior in sentinel crabs (Brachyura: Ocypodoidea: Macrophthalmus). Crustacean Research, 33: 72-91.

Kitaura, J., \& Wada, K., 2006. Evolution of wav- ing display in brachyuran crabs of the genus Ilyoplax. Journal of Crustacean Biology, 26: 455-462.

Koga, T., Murai, M., \& Yong, H.-S., 1999. Malemale competition and intersexual interactions in underground mating of the fiddler crab Uca paradussumieri. Behaviour, 136: 651-667.

Kosuge, T., Murai, M., \& Poovachiranon, S., 1994a. Breeding cycle and mating behaviour of the tropical ocypodid Ilyoplax gangetica (Kemp 1919) (Crustacea Brachyura). Tropical Zoology, 7: 25-34.

Kosuge, T., Poovachiranon, S., \& Murai, M., 1994b. Male courtship cycles in three species of tropical Ilyoplax crabs (Decapoda, Brachyura, Ocypodidae). Hydrobiologia, 285: 93-100.

Murai, M., Goshima, S., Kawai, T., \& Yong, H.-S., 1996. Pair formation in the burrows of the fiddler crab Uca rosea (Decapoda: Ocypodidae). Journal of Crustacean Biology, 16: 522-528.

Murai, M., Koga, T., Goshima, S., \& Poovachiranon, S., 1995. Courtship and the evolution of underground mating in Uca tetragonon (Decapoda: Ocypodidae). Journal of Crustacean Biology, 15: 655-658.

Murai, M., Koga, T., \& Yong, H.-S., 2002. The assessment of female reproductive state during courtship and scramble competition in the fiddler crab, Uca paradussumieri. Behavioral Ecology and Sociobiology, 52: 137-142.

Serène, R., 1968. The Brachyura of the Indo-West Pacific region. Singapore National Academy of Science, Special Publication, 1: 33-112.

Schöne, H., 1968. Agonistic and sexual display in aquatic and semi-terrestrial brachyuran crabs. American Zoologist, 8: 641-654.

Tan, C. G. S., \& Ng, P. K. L., 1994. An annotated checklist of mangrove brachyuran crabs from Malaysia and Singapore. Hydrobiologia, 285: 75-84.

Tina, F. W., Jaroensutasinee, M., \& Jaroensutasinee, K., 2015. Effects of body size, resident status and handedness on fighting behaviour 
of the fiddler crab, Uca bengali. Crustaceana, 88: 775-789.

Tweedie, M. W. F., 1950. Notes on grapsoid crabs from the Raffles Museum. Bulletin of the Raffles Museum, 23: 310-324.

Wada, K., 1981. Growth, breeding, and recruitment in Scopimera globosa and Ilyoplax pusillus (Crustacea: Ocypodidae) in the estuary of Waka River, middle Japan. Publications of the Seto Marine Biological Laboratory, 26: 243-259.

Wada, K., 1994. Earthen structure built by Ilyoplax dentimerosa (Crustacea, Brachyura, Ocypodidae). Ethology, 96: 270-282.

Wada, K., Choe, B.-L., Park, J.-K., \& Yum, S.-S., 1996. Population and reproductive biology of Ilyoplax pingi and I. dentimerosa (Brachyura: Ocypodidae). Crustacean Research, 25: 4453.
Weis, J. S., \& Weis, P., 2004. Behavior of four species of fiddler crabs, genus $U c a$, in southeast Sulawesi, Indonesia. Hydrobiologia, 523: 47-58.

Zucker, N., 1988. Preliminary observations of cheliped use during social activities in sentinel crabs (Brachyura, family Ocypodidae, genus Macrophthalmus) from northern Queensland, Australia. Bulletin of Marine Science, 43: 98-102.

\section{Address}

(KW) IDEA Consultants, Inc. Nanko-kita 124-22, Suminoe-ku, Osaka 559-8519, Japan

\section{E-mail address}

(KW) ilyoplaxkeiji@gmail.com 